Communications in Physics, Vol.20, No. 1 (2010), pp. 91-96

\title{
MONTE-CARLO DETERMINATION OF DOSE RATES IN SPHERICAL PRESSURIZED WATER REACTOR SHIELD
}

\author{
LE VAN NGOC \\ Institute for Nuclear Science and Technology \\ TRINH DANG HA \\ Vietnam Agency for Radiation and Nuclear Safety
}

\begin{abstract}
The nuclear reactor emits various kinds of nuclear radiations during operation. However, the main contributions to the radiation field in the reactor are given by neutrons and gamma rays. These radiation components are the principal concern of reactor shielding. In our study the neutron and gamma radiation dose rates at different depths in concrete bio-shield of the PWR were calculated based on spherical model for $M-C$ simulation with using MCNP4C2. The simulation results were compared with the results obtained from calculations based on $S_{8} P_{3}$ spherical approximation with using the ANISN code.
\end{abstract}

\section{INTRODUCTION}

Operating nuclear reactor is a strong radiation source emitting many types of nuclear radiations. Several different types of potentially dangerous nuclear radiations created in reactor are $\alpha$-particles, $\beta$-particles, recoiling fission fragments, neutrons, neutrinos, and gamma rays. The neutrons and gamma rays are produced simultaneously with the fission event, the fission fragments-highly radioactive nuclides emit $\alpha, \beta$ and $\gamma$-radiation. Neutrinos, due to small probability to interact with matter, do not play practically any role in radiation shielding problem, and is not taken into account in shielding calculations. The charged particles like $\alpha$ 's, $\beta$ 's, and the heavily ionizing fission fragments, are readily stopped within, at most, a few centimeters of a dense material, so that, under normal operating conditions, most of charged particles do not penetrate beyond the fuel elements, and certainly not beyond the reactor core. Therefore, neutrons and gamma rays are the main sources of radiation to give the contributions to the radiation situation in the reactor during operation, and the principal concern of reactor shielding is to attenuate penetrative fast neutrons and energetic secondary $\gamma$-rays released in the core and shield. As the measurements of radiation levels in actual PWR shields are scarce, the calculation of these radiation levels is practically important for analyzing shield of the PWR. In this paper, the neutron and gamma radiation dose rates at various depths in concrete bio-shield of a PWR was calculated in spherical model by Monte-Carlo simulation based on MCNP4C2 [1]. 


\section{MONTE-CARLO CALCULATION OF DOSE RATES IN PWR CONCRETE BIO-SHIELD}

In practice of reactor shielding calculation the PWR may be characterized by a spherical model [2].The assumed geometry of a PWR is specified then in Table 1 . The neutron source distribution is given in Table 2, this distribution corresponds to the condition of operating reactor at power level of 1910 Mwatt.

The radiation field in reactor core is basically composed of neutron and gamma radiation components. Reactor gamma rays are generally divided into two categories primary gamma rays created from fission process or the decay of fission products, and secondary gamma rays originating from the interaction of neutrons with matter, either by neutron capture or by inelastic scattering.

For Monte-Carlo calculation of neutron and gamma radiation dose rates at various depths (from the shield surface) in concrete bio-shield of a PWR in spherical model with characteristics as described in [2] the reactor core is considered as a radiation source. The 30 -group neutron transport and the coupled 30 and 12 group neutron and photon transport (in a single calculation both primary neutrons and primary and secondary photons are taken into account) were simulated based on MCNP4C2 with using source biasing and Russian roulette-splitting techniques for variance reduction in calculations.

The neutrons have been simulated until their energy went down to the energy threshold of $2.5 \cdot 10^{-8} \mathrm{MeV}$ with thermalization in thermal energy range while photons have been simulated until the energy cutoff of $0.01 \mathrm{MeV}$.

The MCNP dose rate at a position in space can be estimated then as

$$
D_{A}=\frac{1}{A} \int_{A} F_{2}\left(r_{A}, E, \Omega\right) f(E) d E d S d \Omega
$$

Here $F_{2}\left(r_{A}, E, \Omega\right)$-surface radiation flux; $f(E)$-flux to dose rate conversion factor; $A$ surface area surrounding the considered position. The flux to dose rate conversion factors for neutrons and photons are given in [3] and have been used in our dose rate calculations.

Table 1. Spherical model for PWR shield calculation

\begin{tabular}{clc}
\hline \hline $\mathrm{N}_{0}$ & Region & Outer radius $(\mathrm{cm})$ \\
\hline \hline 1 & Core & 154.86 \\
2 & Coolant & 170.03 \\
3 & SS barrel & 175.18 \\
4 & Coolant & 181.15 \\
5 & SS thermal shield & 187.96 \\
6 & Coolant & 199.39 \\
7 & SS pressure vessel & 219.39 \\
8 & Void & 237.17 \\
9 & MS liner & 240.98 \\
10 & Concrete & 450.53 \\
\hline \hline
\end{tabular}


Table 2. The neutron source distribution for PWR shield calculation

\begin{tabular}{cc}
\hline \hline Radius $(\mathrm{cm})$ & Source $(\mathrm{n} / \mathrm{cm} 3-\mathrm{sec})$ \\
\hline \hline 5 & $1.00 \mathrm{E} 13$ \\
15 & $1.01 \mathrm{E} 13$ \\
25 & $1.02 \mathrm{E} 13$ \\
35 & $1.05 \mathrm{E} 13$ \\
45 & $1.07 \mathrm{E} 13$ \\
55 & $1.10 \mathrm{E} 13$ \\
65 & $1.13 \mathrm{E} 13$ \\
75 & $1.07 \mathrm{E} 13$ \\
85 & $1.02 \mathrm{E} 13$ \\
95 & $1.04 \mathrm{E} 13$ \\
105 & $1.06 \mathrm{E} 13$ \\
115 & $1.02 \mathrm{E} 13$ \\
125 & $9.80 \mathrm{E} 12$ \\
135 & $9.28 \mathrm{E} 12$ \\
145 & $8.75 \mathrm{E} 12$ \\
154.86 & $8.28 \mathrm{E} 12$ \\
\hline \hline
\end{tabular}

Table 3. The MCNP and ANISN neutron depth dose rates in concrete bio-shield of a PWR in spherical model during operation

\begin{tabular}{|c|c|c|c|c|}
\hline $\mathrm{N}_{0}$ & Depth $(\mathrm{cm})$ & $\begin{array}{c}\text { MCNP neutron dose } \\
\text { rate }(\mathrm{mrem} / \mathrm{hr})\end{array}$ & $\begin{array}{c}\text { ANISN neutrondose } \\
\text { rate }(\mathrm{mrem} / \mathrm{hr})\end{array}$ & $\begin{array}{c}\text { Relative } \\
\text { Difference }(\%)\end{array}$ \\
\hline 1 & 9.02 & $(6.5250 \pm 0.0150) .10^{8}$ & $6.0930 .10^{8}$ & 7.1 \\
\hline 2 & 19.02 & $(1.9349 \pm 0.0064) .10^{8}$ & $1.3900 .10^{8}$ & 39.2 \\
\hline 3 & 29.02 & $(6.8794 \pm 0.0310) .10^{7}$ & $5.1700 .10^{7}$ & 33.1 \\
\hline 4 & 39.02 & $(2.6145 \pm 0.0133) .10^{7}$ & $1.6370 .10^{7}$ & 59.71 \\
\hline 5 & 49.02 & $(1.0374 \pm 0.0073) .10^{7}$ & $5.1700 .10^{6}$ & 100.66 \\
\hline 6 & 59.02 & $(4.1242 \pm 0.0379) .10^{6}$ & $2.2740 .10^{6}$ & 81.36 \\
\hline 7 & 69.02 & $(1.6533 \pm 0.0192) .10^{6}$ & $7.1809 .10^{5}$ & 130.24 \\
\hline 8 & 79.02 & $(6.5433 \pm 0.0903) .10^{5}$ & $2.6800 .10^{5}$ & 144.15 \\
\hline 9 & 89.02 & $(2.6589 \pm 0.0529) .10^{5}$ & $10^{5}$ & 165.89 \\
\hline 10 & 99.02 & $(1.1108 \pm 0.0296) .10^{5}$ & $3.7221 .10^{4}$ & 198.3 \\
\hline 11 & 109.02 & $(4.3969 \pm 0.1627) .10^{4}$ & $10^{4}$ & 339.69 \\
\hline 12 & 119.02 & $(1.7001 \pm 0.0712) .10^{4}$ & $5.1700 .10^{3}$ & 228.4 \\
\hline 13 & 129.02 & $(7.1392 \pm 0.6511) .10^{3}$ & $1.9293 .10^{3}$ & 270.04 \\
\hline 14 & 134.02 & $(4.1411 \pm 0.4178) .10^{3}$ & $10^{3}$ & 314.11 \\
\hline 15 & 209.55 & $(8.0643 \pm 1.2822) .10^{-1}$ & $5.2071 .10^{-1}$ & 54.87 \\
\hline
\end{tabular}

The MCNP dose rates obtained by us from simulation of $2.10^{9}$ source neutrons (for calculation of neutron depth dose rates with 43.5 hours of computer time on PC Pentium 
Table 4. The MCNP and ANISN gamma ray depth dose rates in concrete bioshield of a PWR in spherical model during operation

\begin{tabular}{|c|c|c|c|c|}
\hline No & Depth $(\mathrm{cm})$ & $\begin{array}{c}\text { MCNP gamma dose } \\
\text { Rate }(\mathrm{mrem} / \mathrm{hr})\end{array}$ & $\begin{array}{c}\text { ANISN gamma dose } \\
\text { rate }(\mathrm{mrem} / \mathrm{hr})\end{array}$ & $\begin{array}{c}\text { Relative } \\
\text { Difference }(\%)\end{array}$ \\
\hline 1 & 9.02 & $(3.7728 \pm 0.0264) .10^{7}$ & $4.3867 .10^{7}$ & 14 \\
\hline 2 & 19.02 & $(2.8081 \pm 0.0219) .10^{7}$ & $2.9974 .10^{7}$ & 6.32 \\
\hline 3 & 29.02 & $(1.7773 \pm 0.0144) .10^{7}$ & $1.8725 .10^{7}$ & 5.08 \\
\hline 4 & 39.02 & $(1.0090 \pm 0.0085) .10^{7}$ & $10^{7}$ & 0.9 \\
\hline 5 & 49.02 & $(5.3630 \pm 0.0526) .10^{6}$ & $5.1699 .10^{6}$ & 3.74 \\
\hline 6 & 59.02 & $(2.7774 \pm 0.0325) .10^{6}$ & $2.6797 .10^{6}$ & 3.65 \\
\hline 7 & 69.02 & $(1.2292 \pm 0.1018) .10^{6}$ & $1.1786 .10^{6}$ & 4.29 \\
\hline 8 & 79.02 & $(5.8944 \pm 0.5446) .10^{5}$ & $5.1699 .10^{5}$ & 14.01 \\
\hline 9 & 89.02 & $(3.3816 \pm 0.0680) .10^{5}$ & $2.6800 .10^{5}$ & 26.18 \\
\hline 10 & 99.02 & $(1.6703 \pm 0.0361) .10^{5}$ & $1.3900 .10^{5}$ & 20.17 \\
\hline 11 & 109.02 & $(7.9332 \pm 0.1960) .10^{4}$ & $7.1809 .10^{4}$ & 10.48 \\
\hline 12 & 119.02 & $(3.9258 \pm 0.1182) .10^{4}$ & $3.7221 .10^{4}$ & 5.47 \\
\hline 13 & 129.02 & $(1.9077 \pm 0.0700) .10^{4}$ & $1.6370 .10^{4}$ & 16.54 \\
\hline 14 & 134.02 & $(1.3264 \pm 0.0493) .10^{4}$ & $1.2000 .10^{4}$ & 10.53 \\
\hline 15 & 209.55 & $(7.1435 \pm 0.7458) .10^{1}$ & $6.1663 .10^{1}$ & 15.85 \\
\hline
\end{tabular}

IV, Intel P4 2.66 GHz, Ram 256Mbx2) and $10^{9}$ source neutrons (for caculation of gamma ray depth dose rates with 114 hours of computer time on on PC Pentium IV, Intel P4 2.66 $\mathrm{GHz}$, Ram 256Mbx2) are given in Tables 3 and 4 together with the results obtained from the similar calculations based on $\mathrm{S}_{8} \mathrm{P}_{3}$ spherical approximation with using the ANISN code [2] for comparision. As for total dose rates they are shown out in Table 5.

It is noted that the relative differences between MCNP and ANISN results change from $7.1 \%$ (at depth of $9.02 \mathrm{~cm}$ ) to $339.69 \%$ (at depth of $109.02 \mathrm{~cm}$ ) for neutron depth dose rates, $0.9 \%$ (at depth of $39.02 \mathrm{~cm}$ ) to $26.18 \%$ (at depth of $89.02 \mathrm{~cm}$ ) for gamma ray depth dose rates and $5.67 \%$ (at depth of $9.02 \mathrm{~cm}$ ) to $64.14 \%$ (at depth of $89.02 \mathrm{~cm}$ ) for total depth dose rates, respectively. At the outermost shield surface (corresponding to the depth of $209.55 \mathrm{~cm}$ ) the above relative difference is $54.87 \%$ for neutron dose rate and $15.85 \%$ for gamma ray dose rate while for total dose rate this relative difference is $16.17 \%$

The differences between MCNP and ANISN depth dose rates may be explained by the fact that the different computational methods and nuclear data sources are used in MCNP4C2 and ANISN codes. Meanwile dose rate calculations with using MCNP4C2 are based on Monte-Carlo method (probabilistic method of calculation) and cross-section data taken from multigroup data library ENDF-V for 30 and 12 group neutron and photon transport calculation, similar calculations with using the ANISN code are based on discrete ordinate method (deterministic method of calculation) and cross-section data taken from DLC-23/CASK [4] for 22 group neutron transport and 18 group photon one. Besides, in 
Table 5. The MCNP and ANISN total depth dose rates in concrete bio-shield of a PWR in spherical model during operation

\begin{tabular}{|c|c|c|c|c|}
\hline \hline No & Depth (cm) & $\begin{array}{c}\text { MCNP total dose } \\
\text { Rate (mrem /hr) }\end{array}$ & $\begin{array}{c}\text { ANISN total dose } \\
\text { rate (mrem /hr) }\end{array}$ & $\begin{array}{c}\text { Relative } \\
\text { difference (\%) }\end{array}$ \\
\hline \hline 1 & 9.02 & $6.9023 .10^{8}$ & $6.5317 .10^{8}$ & 5.67 \\
\hline 2 & 19.02 & $2.2157 .10^{8}$ & $1.6897 .10^{8}$ & 31.13 \\
\hline 3 & 29.02 & $8.6567 .10^{7}$ & $7.0425 .10^{7}$ & 22.92 \\
\hline 4 & 39.02 & $3.6235 .10^{7}$ & $2.6370 .10^{7}$ & 37.41 \\
\hline 5 & 49.02 & $1.5737 .10^{7}$ & $1.0340 .10^{7}$ & 52.12 \\
\hline 6 & 59.02 & $6.9016 .10^{6}$ & $4.9537 .10^{6}$ & 39.32 \\
\hline 7 & 69.02 & $2.8825 .10^{6}$ & $1.8967 .10^{6}$ & 51.98 \\
\hline 8 & 79.02 & $1.2438 .10^{6}$ & $7.8499 .10^{5}$ & 58.45 \\
\hline 9 & 89.02 & $6.0405 .10^{5}$ & $3.6800 .10^{5}$ & 64.14 \\
\hline 10 & 99.02 & $2.7811 .10^{5}$ & $1.7622 .10^{5}$ & 57.82 \\
\hline 11 & 109.02 & $1.2330 .10^{5}$ & $8.1810 .10^{4}$ & 50.72 \\
\hline 12 & 119.02 & $5.6259 .10^{4}$ & $4.2391 .10^{4}$ & 32.72 \\
\hline 13 & 129.02 & $2.6216 .10^{4}$ & $1.8299 .10^{4}$ & 43.27 \\
\hline 14 & 134.02 & $1.7442 .10^{4}$ & $1.3000 .10^{4}$ & 34.17 \\
\hline 15 & 209.55 & $7.2241 .10^{1}$ & $6.2184 .10^{1}$ & 16.17 \\
\hline \hline
\end{tabular}

our MCNP dose rate calculations the flux to dose rate conversion factors were determined based on data given in [3] by linear or logarithmic interpolations for each energy of a neutron or photon, but for ANISN dose rate calculation one has used flux to dose rate conversion multipliers for 22 and 18 group neutron and photon structures.

\section{CONCLUSION}

The neutrons and gamma rays are the radiation components giving the main contributions to the radiation situation in the operating reactor. Calculation of radiation levels in PWR shield is practically important for shield analysis. In this study the neutron and gamma ray dose rates at different depths in a concrete bio-shield of PWR were calculated for spherical model by M-C simulation with using MCNP4C2. The comparison of MCNP and ANISN-based calculation results showed that the MCNP and ANISN dose rates are in large difference for neutron, but they are in good agreement with errors lower than $26 \%$ for gamma. Especially at the outermost shield surface the MCNP and ANISN-based calculation results are in good agreement for gamma dose rate as well as for the total dose rate with errors around of $15-16 \%$. 


\section{REFERENCES}

[1] MCNP4C2 - Monte-Carlo N-particle Transport Code System, Oak Rid.ge National Laboratory, Radiation Safety Information and Computational Center, U.S.A, 2001.

[2] American National Standard ANSI/ANS-6.4-1997.

[3] American National Standard ANSI/ANS-6.4-1977.

[4] RSIC Data Library DLC-23/CASK, 40-Group Coupled Neutron and Gamma-Ray Cross- Sectional Data, ORNL-RSIC, revised 1973.

[5] A. A. Abagian et al., Secondary Gamma-radiation in Radiative Shielding, Moscow, Energoatomizdat, 1984.

Received 05 May 2009. 